\title{
Ideal Investment Protection in Optimistic Perceptions: Evidence From the Indian Equity Options Market
}

\author{
Babu Jose ${ }^{1} \&$ James Varghese ${ }^{1}$ \\ ${ }^{1}$ Department of Commerce, St. Thomas College, Palai, Kottayam, Kerala, India \\ Correspondence: James Varghese, Assistant Professor, Department of Commerce, St. Thomas College, Palai, \\ Kottayam, Kerala, India. Tel: 91-90-4871-0208.
}

Received: September 18, 2020

Accepted: November 12, 2020

Online Published: January 15, 2021

doi:10.5430/ijfr.v12n2p327

URL: https://doi.org/10.5430/ijfr.v12n2p327

\begin{abstract}
The study is an experiential assessment on the ability of the Indian equity options market to resist the adverse impacts that arise from unexpected changes in the underlying equity market, focusing on two distinct investor perceptions within optimistic dimension in the market, viz. the recovery phase and the growth phase, which were evident in the Indian market scenario post the period of financial upheavals due to global economic crisis during the latter half of 2000s. The risk mitigation capability of the options is examined in terms of long run integration and short run re-equilibrating relationship shown by near month calls and puts with varied stages of exercisability with their underlying equity segment in the National Stock Exchange of India. Further, the ideal hedge sizes of the options and the hedge gains resulting from affecting them in the investment profile are identified under minimum variance framework, using Diagonal BEKK GARCH. The results are indicative that all different options segments express to have the expected resistance ability during both bullish perceptions under consideration, and prove that optimal use of options with equity portfolio provides assured hedge gains in terms of reduction in un-anticipatable variances.
\end{abstract}

Keywords: ideal investment protection, hedge size, hedge gains, minimum variance hedge, diagonal BEKK GARCH, optimistic perceptions, Indian equity options market

\section{Introduction}

From the post financial crisis period spanning from the end of 2008, the Indian equity market expresses to have substantial expansion with a persistent bullish dimension, and a perceptional change is identifiable around November 2013, when the market regained its position prior to the steep fall caused by the crisis. As Figure 1 indicates, the first phase is a period of recovery from the upshots of global financial meltdown where the investors are stressed due to the risk implied in their positions that are far below an early optimistic level, and the second phase, which denotes a period of growth after the recovery stage, indicates a persisting optimism with less risk dimensions due to its new heights, probably backed by stubborn economic strength of the financial system. As the furtherance of development of any economic sphere is subject to its ability in attracting productive investments to its financial markets by facilitating resistance to undesirable market momentums, the responses of the system to the changes in the market perceptions gain standing in the empirical literature.

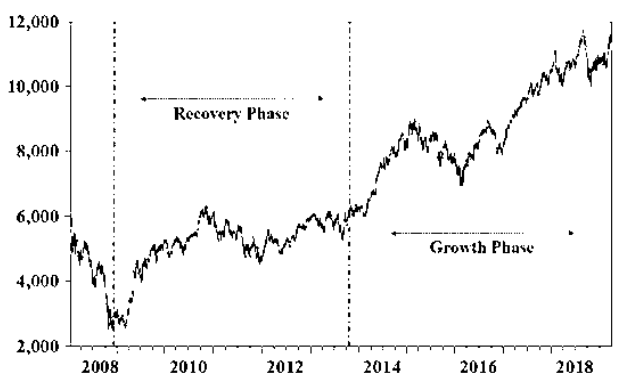

Figure 1. Historical movement of the NSE Nifty 50 index representing the recovery phase and the growth phase of the underlying market of Indian equity options 
Considering risk perceptions and investment preferences of the market participants (Yang, Lee, \& Ryu, 2017) in choosing either call or put options with varied levels of exercisability (Bond \& Thompson, 1985), the study intends to explore the potential gains from hedging equity investments in the Indian capital market, using the financial options on them at an ideal size, with remarkable highlights on two different phases of bull domination in the market. The contributions of the present study to the finance literature are three-fold. First, it suggests a compilation of experiential methodologies for developing time series for the options market. Secondly, it estimates ideal proportions for holding diverse equity options so as to effect mitigation of uncertainties in the equity market to a maximum possible extent and the resulting gains from such hedges following minimum variance framework, instead of widely used approaches based on different options pricing models. Moreover thirdly, adding to the uniqueness of the study, it compares the efficacy of the equity options market to offer exploitable risk mitigation focusing two distinct perceptions in the bullish dimension of the equity market.

\section{Review of Literature}

An equity market is considered effectual when it is supported by active derivative markets for advanced risk mitigation (Ross, 1976), where derivatives are designed to transfer the effects of uncertain future events in the market to risk-lovers from risk-averters (Ederington, 1979). Amongst various derivatives, the options appeal to have effective risk reduction without compromising the benefits from profitable changes in the underlying market. Evaluations of the resistance raised by the options market to offset adverse trends in the stock market are based on the theory that a market is efficient when it does not allow the participants to gain abnormal and excess earnings from it (Fama, 1970), and the initial examinations were on the predictability of the options prices using various theoretical models (Evnine \& Rudd, 1984). Other empirical methods for scrutinizing the ability of the options market to perform its fundamental function are assessments of internal market efficiency as well as cross market efficiency, where the former is measured in terms of no-arbitrage association prevailing within the options market (Aggarwal \& Gupta, 2009; Zhang \& Watada, 2019) and the latter is assessed with regard to the arbitrage free affiliations among the options and other markets (Kamara \& Miller, 1995; Vipul, 2008; Mutum \& Das, 2019). But these methods seldom validate the prime purpose of the options, as they fail to account for instantaneous simultaneity among the options market and its underlying spot market in reflecting substantial information (Chan, Chung, \& Johnson, 1993), which leads to arbitrage earnings (Hentze \& Seiler, 2000). Even though market frictions and other inconsistencies may cause these lead-lag relationships (Abhyankar, 1995), the pecuniary motivations from the options market, including greater flexibility, leverage and liquidity and lesser transaction costs (Fleming, Ostdick, \& Whaley, 1996; Easley, O'Hara, \& Sreenivas, 1998; Chakravarthy, Gulen, \& Mayhew, 2004) find basis for nullification of a general notion that the options segment replicate only information already reflected in the equity market. Information share of the options market is owing to the informed participants who initially trade in the options to gain deliberate advantages (Kang \& Park, 2014), and its cumulative effect develops the options market as an enhanced reservoir of information on further equity movements (Ryu, 2016). But Kim, Kim, and Nam (2009), Muravyev, Pearson, and Broussard (2013) and Mazouz, Wu, and Yin (2015) propose relative information absorption in the equity segment. Empirical evidences from India find no exemption in this, and remain inconclusive, where Srivastava (2003), Mukharjee and Mishra (2004), Debasish (2009) and Bagchi (2012) argue in favor of the options and Dixit, Yadav, and Jain (2010) and Shaikh and Padhi $(2013 ; 2015)$ support initial reflection of information in the stock market.

The relative speed of reflecting information in the options segment and its underlying spot market are subject to various sensitive market circumstances (Ren, Ji, Cai, Li, \& Jiang, 2019), and this temporal connections resulting from short run dynamism alone do not warrant that the options segment is suitable for facilitating the protection of investors from unwanted changes in the equity market, unless otherwise proved that both the markets move in tandem, easing the investors to offset the aftermaths of uncertainties in one market by reversing the position in the other market. When the pre-projected monotonous co-movements between the options and spot markets are violated, it is obvious that the former is unable to defuse the consequences of antagonistic movements in the latter (Bakshi, Cao, \& Chen, 2000b). Thus, appropriateness of the options market for risk mitigation initiatives is evident when it expresses to maintain a long run co-movement with the underlying equity market (Hull \& White, 2017). In other words, the important prerequisite for the options market to be able to minimize the effects of inexact deviations is the presence of integration between both the market counterparts. Therefore, the ability of the options market to raise resistance to the impacts of risk implied in the spot market is to be confirmed by estimating how effectively both the spot and derivative segments interact with each other to develop an equilibrating momentum between them, so as to invalidate the consequences of non-instantaneous informational absorption between both the streams (Kim, et al., 2009). 
The knowledge on the usefulness of the options market in reducing the effects of risk exposure is worth only when it fetches out an ideal size at which the options facilitate lessening of the effects to a maximum possible extent (Choudhry, 2004), and the level of gain arising from such hedging strategies using the ideal size denotes the efficacy of the options market and becomes a benchmark for decision making (Cao \& Huang, 2007; Hull \& White, 2017). The identification of a risk dilution strategy that uses options on the spot at an ideal size is contingent upon the risk perceptions of the investors (Bond \& Thompson, 1985), but surely is capable of enhancing the efficacy of the strategy (Kamara \& Siegel, 1987). Modes for assessing the 'hedge gains' are also momentous for the practitioners (Brailsford, Corrigan, \& Heaney, 2001), and amid minimum variance hedge (Ederington, 1979) and utility maximization hedge (Cecchetti, Cumby, \& Figlwiski, 1988), the latter tends to converge in to the former, which considers hedging as formation of a perfect trade-off between risk and return, when both derivatives and spot markets expresses to have joint normality, especially for extended hedging horizons (Chen, Lee, \& Shrestha, 2003; 2008). Empirical studies propose various methods for computation of ideal hedge size. The conveniently adoptable conventional method is oridinary least square (OLS) regression (Ederington, 1979), but its empirical consistency is interrogated as it does not consider co-integration among the market counterparts and short run dynamics among them in the estimation (Lien D.-H. D., 1996). The use of vector autoregression and error correction models are also questioned owing to their inability to screen the effects of dynamism among the markets (Lien \& Tse, 1999; Floros \& Vougas, 2006; Kenourgios, Samitas, \& Drosos, 2008). But the Autoregressive Conditional Heteroskedasticity (ARCH) based dynamic models result in better estimation of ideal hedge size (Park \& Switzer, 1995a; 1995b; Lien \& Tse, 1999; Floros \& Vougas, 2006), as an improved hedging performance is expected from the incorporation of conditional heteroskedasticity in to the estimation (Bai, Pan, \& Liu, 2019). François, Gauthier, and Godin (2014) and Zhipang and Shenghong (2017) propose the use of Diagonal BEKK-GARCH model for estimating an ideal hedge size. Evidences from the futures market in India also support GARCH models in the estimation (Kumar, Singh, \& Pandey, 2008; Bhaduri \& Durai, 2008; Gupta \& Singh, 2009; Lagesh \& Padhi, 2009; Singh, 2017). Pragmatic literature on the options holds that ideal hedge size is an integral part of various pricing models (Bakshi, Cao, \& Chen, 1997; 2000a; Dumas, Fleming, \& Whaley, 1998; An \& Suo, 2009). But, following Rao and Thakur (2008) who find the outperformance of hedge sizes proposed by Ederington (1979) and Black and Scholes (1973) in Indian derivative segments, DeMaskey (1995), Bakshi, et al. (2000a), Butterworth and Holmes (2001), Alexander and Nogueira (2007) and Hull and White (2017) hold that the minimum variance approach is appropriate for the estimation of hedge gains. However, the empirical evaluations on the hedging performance of options are studied from an option trader's perspective (Alexander \& Nogueira, 2007; Hull \& White, 2017), signifying the scope of the current study to focus on investor perspectives.

\section{Methods}

The data used to represent the Indian equity and equity options markets are daily closing values of NSE Nifty 50 index and of implied index computed from actual values of options on the index (Debasish, 2009). Manaster and Rendleman (1982) proposed the idea of implied stock level to indicate the value of the underlying asset perceived from the actual options prices. The implied index levels for all options considered in the study are determined by inverting the Black and Scholes (1973) model using the Newton-Raphson process. From the transaction data on simultaneously traded multiple options, time series is formed by selecting one contract having utmost trade volume on a trade day from near month options alone with at least one transaction on a day (Dixit, et al., 2010), but with a shift to subsequent maturity cycle before eight days to expiration (Debasish, 2009), after filtering for violations of arbitrage boundaries (Jiang \& Tian, 2011) and classifying in to at-the-money (ATM), out-of-the-money (OTM), in-the-money (ITM), deep-out-of-the-money (DOTM) and deep-in-the-money (DITM) (Yang, Lee, \& Ryu, 2017) call and put options.

Following the examination of fundamental properties of the data, the resistance capacity of the options market to vagaries in the stock market is scrutinized by examining the integration of the options market with its underlying equity market, using Trace and maximum Eigen value tests in the Johansen's cointegration framework (Holowczak, Simaan, \& $\mathrm{Wu}, 2006)$, based on the relationship given equation (1).

$$
P_{j, t}-\hat{\beta}_{0}-\hat{\beta}_{1} P_{s, t}=\hat{\epsilon}_{o, t}
$$

The strength of the risk reduction ability of the options markets is analyzed from the short run dynamic association of the options market with the equity market using vector error correction model (VECM) (Holowczak, et al., 2006), using equation (2) and (3).

$$
r_{s, t}=\alpha_{1}+\alpha_{s} \hat{e}_{j, t-1}+\sum_{k=1}^{n} \alpha_{11}(k) r_{s, t-k}+\sum_{k=1}^{n} \alpha_{12}(k) r_{j, t-k}+\hat{\epsilon}_{s, t}
$$




$$
r_{j, t}=\alpha_{1}+\alpha_{j} \hat{e}_{j, t-1}+\sum_{k=1}^{n} \alpha_{21}(k) r_{s, t-k}+\sum_{k=1}^{n} \alpha_{22}(k) r_{j, t-k}+\hat{\epsilon}_{j, t}
$$

After scrutinizing the heteroskedasticity of the data series using ARCH-LM test, variances in the daily returns of the options and the equity markets and covariance of the both are estimated by Diagonal BEKK GARCH model (Zhipang \& Shenghong, 2017), using equation (4).

$$
H_{t}=\left(\begin{array}{ll}
H_{s s, t} & H_{s o, t} \\
H_{o s, t} & H_{o o, t}
\end{array}\right)=C^{\prime} C+\sum_{k=1}^{p} A_{k}^{\prime} \epsilon_{t-k} \epsilon_{t-k}^{\prime} A_{k}+\sum_{k=1}^{p} B_{k}^{\prime} H_{t-k} B_{k}
$$

Finally, the ideal hedge size and the hedge gains from them are assessed under minimum variance framework (Ederington, 1979; Lien D., 2009) using equations (5) and (6) respectively.

$$
\begin{gathered}
\text { Ideal Hedge Size }=\frac{\operatorname{Cov}\left(\Delta S_{t} \Delta O_{t}\right)}{\sigma_{\Delta O_{t}}^{2}} \\
\text { Hedge Gain }=\frac{\sigma_{\Delta S_{t}}^{2}-\left(\sigma_{\Delta S_{t}}^{2}+H_{t-1}^{2} \sigma_{\Delta O_{t}}^{2}+2 H_{t-1} \operatorname{Cov}\left(\Delta S_{t} \Delta O_{t}\right)\right)}{\sigma_{\Delta S_{t}}^{2}}
\end{gathered}
$$

\section{Empirical Analysis and Discussion}

\subsection{Do the Options Protect Equity Investments?}

The movements of the call and put options markets are found to be related with that of the equity market by comparing their historical movements throughout both the phases under consideration, and close co-movements that suggest long run integration amongst the options-spot market pairs in each of the circumstances (Bakshi, et al., $2000 \mathrm{~b}$ ) are identified. While proceeding to advanced econometric assessments, the data structure, which is identified to have nonconformities with the general expectations, is reframed (Alexander \& Nogueira, 2007). Further, the stationarity checks prove the general anticipation that the price series may have inducements from their own past (Kim, et al., 2009), inclining again potential integration among the market pairs (Holowczak, et al., 2006). [The results of unit root tests for stationarity are given as Appendix A1.]

The options market can help investors to resist the unfavorable effects from price changes in the spot market, only when it has close long run integration with the spot counterpart. Table 1 explains the level of integration present among different equity options segments under the study with their underlying equity market, for both the recovery and growth phases of the Indian stock market. In line with the general expectation formed from the preliminary analysis, all the options, viz. ATM, OTM, ITM, DOTM and DITM calls and puts markets are integrated with the equity market, and the results, given in Table 1, do not get changed in correspondence with the shift in the risk perception of the investors, as Trace and Maximum Eigen-value tests in the Johansen's framework reject the premises of no cointegration and fail to reject that of one cointegration among each of the options-spot pairs.

However, mere presence of integration among the options markets and their underlying spot market cannot guarantee that the derivative segment can be efficiently used for risk mitigation, since the integration measures only the long-run co-movement without considering the short run deviations of the markets from the equilibrium. Table 2 explains the level of promptness of both the markets to readjust itself to the integration with the other market, under both times under consideration. The VECM results highlight that the deviations are readjusted back within a short span of time, and the market system is in a dynamism that does not allow the component markets to deviate far from the equilibrating affiliations.

During the recovery phase, even though, the equity market in correspondence with the ITM and DITM call options and ATM, OTM, ITM, DOTM and DITM put options tends to lead in the readjustment process taking 117, 76, 55, $42,21,88$ and 34 days respectively, it is found that such processes are not significant to denote a leading role from the equity market. But from the options market, it is clear that the price rebalancing process takes place within it and the processes are statistically significant. It is also noteworthy that ATM, OTM, ITM, DOTM and DITM call options markets take only $13,14,6,5$ and 4 trade days respectively to regain the integration with the equity market, and ATM, OTM, ITM, DOTM and DITM put options markets regain the equilibrium within 9, 11, 3, 7 and 2 days respectively. Post the dimensional shift, during the growth phase, the equity market that correspond with the ATM and OTM call options and all the put options markets show slight tendency to regain the equilibrium state, but such efforts are not able to mark significant results, except in the case of the DITM put options. The number of days expected by the spot markets of ATM and OTM calls and ATM, OTM, ITM, DOTM and DITM puts are 87, 137, 96, 62, 69, 102 and 9 days. Comparing the above with the informational role of the options segments, it is found that the 
price rebalancing role played by them is significant in the ten situations. It is also noted that the number of days required by the options segments are extremely lower than those required by the spot markets. The ATM, OTM, ITM, DOTM and DITM call options markets take 5, 7, 4, 3 and 5 days respectively to regain the integration with the equity market, and the time taken by the ATM, OTM, ITM, DOTM and DITM put options markets for rebalancing themselves towards the equilibrium are 7, 9, 4, 3 and 2 days respectively. Thus the results undoubtedly confirm the ability of the equity options market in India to protect the equity investments from unforeseen price fluctuations irrespective of the differences in the continuing momentum of the underlying market.

Table 1. Integration among the stock and the options markets

\begin{tabular}{|c|c|c|c|c|c|c|c|c|c|}
\hline & \multirow{2}{*}{$\begin{array}{l}\text { No. of } \\
\text { CE(s) }\end{array}$} & \multicolumn{4}{|c|}{ The Recovery Phase } & \multicolumn{4}{|c|}{ The Growth Phase } \\
\hline & & Trace & Prob. & Max-Eigen & Prob. & Trace & Prob. & Max-Eigen & Prob. \\
\hline \multicolumn{10}{|c|}{ Panel A: Call Options } \\
\hline \multirow{2}{*}{ ATM } & None * & 53.450 & 0.000 & 46.827 & 0.000 & 110.998 & 0.000 & 108.567 & 0.000 \\
\hline & At most 1 & 6.623 & 0.386 & 6.623 & 0.386 & 2.431 & 0.119 & 2.431 & 0.119 \\
\hline \multirow{2}{*}{ OTM } & None * & 34.616 & 0.003 & 27.464 & 0.003 & 61.926 & 0.000 & 59.829 & 0.000 \\
\hline & At most 1 & 7.151 & 0.329 & 7.151 & 0.329 & 2.097 & 0.148 & 2.097 & 0.148 \\
\hline \multirow{2}{*}{ ITM } & None * & 78.837 & 0.000 & 71.017 & 0.000 & 158.598 & 0.000 & 156.224 & 0.000 \\
\hline & At most 1 & 7.820 & 0.267 & 7.820 & 0.267 & 2.374 & 0.123 & 2.374 & 0.123 \\
\hline \multirow{2}{*}{ DOTM } & None * & 86.210 & 0.000 & 79.070 & 0.000 & 141.535 & 0.000 & 139.547 & 0.000 \\
\hline & At most 1 & 7.140 & 0.330 & 7.140 & 0.330 & 1.988 & 0.159 & 1.988 & 0.159 \\
\hline \multirow{2}{*}{ DITM } & None * & 135.611 & 0.000 & 128.824 & 0.000 & 144.723 & 0.000 & 142.407 & 0.000 \\
\hline & At most 1 & 6.787 & 0.367 & 6.787 & 0.367 & 2.316 & 0.128 & 2.316 & 0.128 \\
\hline \multicolumn{10}{|c|}{ Panel B: Put Options } \\
\hline \multirow{2}{*}{ ATM } & None * & 50.802 & 0.000 & 44.030 & 0.000 & 75.954 & 0.000 & 73.564 & 0.000 \\
\hline & At most 1 & 6.773 & 0.369 & 6.773 & 0.369 & 2.389 & 0.122 & 2.389 & 0.122 \\
\hline \multirow{2}{*}{ OTM } & None * & 46.028 & 0.000 & 39.513 & 0.000 & 43.855 & 0.000 & 41.981 & 0.000 \\
\hline & At most 1 & 6.514 & 0.398 & 6.514 & 0.398 & 1.874 & 0.171 & 1.874 & 0.171 \\
\hline \multirow{2}{*}{ ITM } & None * & 100.966 & 0.000 & 93.499 & 0.000 & 129.091 & 0.000 & 126.724 & 0.000 \\
\hline & At most 1 & 7.467 & 0.298 & 7.467 & 0.298 & 2.367 & 0.124 & 2.367 & 0.124 \\
\hline \multirow{2}{*}{ DOTM } & None ${ }^{*}$ & 70.320 & 0.000 & 63.640 & 0.000 & 101.683 & 0.000 & 99.880 & 0.000 \\
\hline & At most 1 & 6.680 & 0.379 & 6.680 & 0.379 & 1.803 & 0.179 & 1.803 & 0.179 \\
\hline \multirow{2}{*}{ DITM } & None * & 100.981 & 0.000 & 92.870 & 0.000 & 200.633 & 0.000 & 198.211 & 0.000 \\
\hline & At most 1 & 8.112 & 0.243 & 8.112 & 0.243 & 2.422 & 0.120 & 2.422 & 0.120 \\
\hline
\end{tabular}

Source: Calculations of the researcher

Note: 'No. of $\mathrm{CE}(\mathrm{s})$ ' stands for 'number of cointegrating equations'. 'Trace' and 'Max-Eigen' stand for 'Trace Statistics' and 'Maximum Eigenvalue Statistics', the tests used to empirically evaluate the null hypothesis that 'there is no cointegrating equation' or 'there is at most one cointegrating equation' as the case may be. 
Table 2. Short run dynamics between the stock and the options market

\begin{tabular}{lcccccccc}
\hline & \multicolumn{3}{c}{ The Recovery Phase } & \multicolumn{3}{c}{ The Growth Phase } \\
\cline { 2 - 11 } & \multicolumn{2}{c}{ Spot } & \multicolumn{2}{c}{ Options } & \multicolumn{2}{c}{ Spot } & Options \\
\cline { 2 - 11 } & EC Coeff. & Prob. & EC Coeff. & Prob. & EC Coeff. & Prob. & EC Coeff. & Prob. \\
\hline Panel A: Call Options & & & & & & & \\
\hline ATM & 0.021 & 0.518 & -0.077 & 0.022 & -0.012 & 0.529 & -0.221 & 0.000 \\
\hline OTM & 0.008 & 0.755 & -0.070 & 0.003 & -0.007 & 0.601 & -0.135 & 0.000 \\
\hline ITM & -0.009 & 0.817 & -0.159 & 0.000 & 0.005 & 0.820 & -0.225 & 0.000 \\
\hline DOTM & 0.011 & 0.487 & -0.204 & 0.000 & 0.007 & 0.444 & -0.346 & 0.000 \\
\hline DITM & -0.013 & 0.634 & -0.232 & 0.000 & 0.021 & 0.223 & -0.196 & 0.000 \\
\hline Panel B: Put Options & & & & & & & & \\
\hline ATM & -0.019 & 0.564 & -0.108 & 0.009 & -0.010 & 0.585 & -0.137 & 0.000 \\
\hline OTM & -0.024 & 0.362 & -0.089 & 0.006 & -0.016 & 0.315 & -0.111 & 0.000 \\
\hline ITM & -0.047 & 0.404 & -0.325 & 0.000 & -0.015 & 0.653 & -0.289 & 0.000 \\
\hline DOTM & -0.011 & 0.567 & -0.149 & 0.000 & -0.010 & 0.356 & -0.321 & 0.000 \\
\hline DITM & -0.030 & 0.788 & -0.517 & 0.000 & -0.115 & 0.050 & -0.538 & 0.000 \\
\hline
\end{tabular}

Source: Calculations of the researcher

Note: 'EC Coeff.' stands for the error correction coefficient in the VECM. The number of trade days required by each market segment to correct the disequilibrium is computed by the formula, No. of days $=1 / \mathrm{EC}$ Coeff.

\subsection{Prospective or Existing Investors: Who Bags More Gains?}

Mere evidence on the ability of the options market to support the equity investors may misguide them by an inherent appeal for naïve hedging, where the hedge portfolio is suggested to have equal number of spot asset and options contracts. The ideal hedging proposes to have an improved assortment of assets and instruments, which results in maximum probable savings from undesirable influences of the uncertain spot movements, but with minimal additional cash outlay for inclusion of options into the portfolio. The minimum variance hedge intimates a ratio for conception of an ideal spot-options portfolio that reduces the unforeseen variances to its minimum possible extent (Ederington, 1979), and the level of variance reduction explains the relative effectiveness of the market that support the hedge portfolio (Cao \& Huang, 2007; Hull \& White, 2017). Even when the market shares an upbeat momentum, both existing as well as prospective investors are subject to the risk exposure, as the market may move further unexpectedly upward or downward. In general, the willingness of investors with ample financial resources to lay out the same consistent with their predispositions on uncertainties determine the investment preferences, and therefore, the efficiency of a spot-options portfolio, shaped for risk dilution drives, tends to vary according to the perceptions of investors (Chuang, Wang, Yeh, \& Chuang, 2015). Furthermore, the decision on selection of the options for achieving effective hedge depends on the tradeoff between the perception of investors towards probable uncertainties and their preparedness to pay initial financial outlay (Ederington, 1979; Bond \& Thompson, 1985).

Table 3 explains an ideal hedge size under minimum variance framework for all the call and put options markets under consideration during the recovery as well as the growth dimensions of the market. [The results of ARCH-LM tests and D-BEKK GARCH estimation are given as Appendix A2 and A3.] Even though both dimensions share common upbeat trend, the perceptional shift seems to influence the required hedge size of the options and the risk reduction efficacy of the options segments. The recovery phase presumes to be riskier than the growth facet, as the former is subject to a pressure to recapture its earlier position whereas the latter strives to grow further to new historical peaks. Further, calls and puts are supportive to the proposed or the existing long positions, respectively, in the underlying market, and they can be used either separately or collectively for the hedging purposes. Considering the moneyness level of the options, ATM options are chosen by those who do not expect the underlying market to move further in either directions in the short run without incurring further cash outlay to book superfluous profits, whereas those expect further favorable changes in the level of underlying asset may opt to trade ITM options that 
fetch assured profits but with higher financial outlay. OTM options are chosen by those expect the market to move unfavorably, so that they can protect the value of their asset at minimal financial outlay. The DITM and DOTM options are suitable for extreme risk takers who are desirous of either utilizing the profitability or protecting the risks at any cost.

Table 3. Optimal hedge size and hedging gains

\begin{tabular}{llcccc}
\hline \multirow{5}{*}{ Option Type } & & \multicolumn{2}{c}{ The Recovery Phase } & \multicolumn{2}{c}{ The Growth Phase } \\
\cline { 2 - 6 } & Moneyness & $\begin{array}{c}\text { Optimal } \\
\text { Hedge Size }\end{array}$ & Hedging Gain & $\begin{array}{c}\text { Optimal } \\
\text { Hedge Size }\end{array}$ & Hedging Gain \\
\hline \multirow{5}{*}{ Call Options } & ATM & 0.82 & $74.05 \%$ & 0.41 & $39.67 \%$ \\
\cline { 2 - 6 } & OTM & 0.72 & $53.08 \%$ & 0.31 & $19.93 \%$ \\
\cline { 2 - 6 } & ITM & 0.81 & $72.20 \%$ & 0.53 & $38.12 \%$ \\
\cline { 2 - 6 } & DOTM & 0.29 & $19.67 \%$ & 0.06 & $05.03 \%$ \\
\cline { 2 - 6 } & DITM & 0.57 & $40.97 \%$ & 0.30 & $11.90 \%$ \\
\hline \multirow{3}{*}{ Put Options } & ATM & 0.73 & $89.98 \%$ & 0.55 & $71.61 \%$ \\
\cline { 2 - 6 } & OTM & 0.70 & $85.92 \%$ & 0.51 & $63.29 \%$ \\
\cline { 2 - 6 } & ITM & 0.74 & $80.65 \%$ & 0.57 & $56.88 \%$ \\
\cline { 2 - 6 } & DOTM & 0.52 & $62.20 \%$ & 0.14 & $18.83 \%$ \\
\cline { 2 - 6 } & DITM & 0.80 & $76.92 \%$ & 0.85 & $78.33 \%$ \\
\hline
\end{tabular}

Source: Calculations of the researcher

\subsubsection{Changing Perceptions and Prospective Investors}

Whenever the market shows a recovery trend after a deep fall owing to any reason, the call options assist the prospective buyers. When the market is expected not to make further sharp changes, the investors can reduce their exposure by a variance reduction of $74.05 \%$, if they hold ATM calls at a ratio of 0.82 for the estimated investments. If the expectation is that the price level in the equity market is yet to increase, the use of OTM calls at an ideal hedge size of 0.72 can provide an average hedge gain of $53.08 \%$. When the prospective investors wish to take maximum advantage from the expected growth in the price level, the advanced long position in the ITM calls at an ideal level of 0.81 will draw $72.20 \%$ variance reduction in the return of future portfolio, but with enhanced cash outlay, whereas the DITM calls provide only $40.97 \%$ hedge gains from its ideal size of 0.57 . The DOTM calls are also less effective as they provide only $19.67 \%$, but from an optimal hedge size of 0.29 .

In line with the general expectation that a still-to-be-developed stock market, like Indian scenario, will move upward in the long run, the investors can make use of the information on the nature and behavior of the options market for reducing their exposure to the maximum possible extent by replicating the hedge portfolio of the growth phase. In this phase, the holding of ATM options at the suggested ideal hedge size of 0.41 to protect the potential investment opportunities from further rise in the price level may provide a hedge gain of $39.67 \%$, and use of OTM calls for the purpose at an ideal level of 0.31 protect the investment only up to $19.93 \%$, whereas DOTM calls at their optimal size of 0.06 provides only negligible risk reduction of $05.03 \%$. When the market keeps its upward pace, the future buyers can take at most advantages by opting to long in ITM or DITM calls, based on their capability for initial financial outlays, and holding them at a ratio of 0.53 or 0.30 , as the case may be, may result in an average hedging gain of $38.12 \%$ or $11.90 \%$, respectively.

\subsubsection{Strategic Compositions for Existing Investors}

For the existing investors, ideal investment protection is possible from formation of portfolios composed of options along with the existing equity assets. The analysis on the recovery stage elaborates, on an average, how either the equity or single stock options market is expected to behave in similar market circumstances. With an anticipation that the market will remain stagnant, at least for some time, inclusion of ATM put options in to the existing equity portfolio at rate of 0.73 reveals to generate an average hedge gain of $89.98 \%$. If the intention of the investors using 
options is to limit the effects caused from unexpected falls, opting OTM puts at an ideal level of 0.70 will result in $85.92 \%$ hedge gains, and the DOTM puts are expected to result in a variance reduction of $62.20 \%$ from its optimal hedge size of 0.52 . When the intention of the existing investors is to have guaranteed gains even from the corrective downtrends in the equity market, the use of ITM puts having moderately high financial outlay as well as DITM puts having extremely high financial outlay, at their corresponding optimal levels of 0.74 and 0.80 is expected to provide approximate hedging gains of $80.65 \%$ and $76.92 \%$, respectively.

The investors with long position in the equity market are not subject to greater risks, since they expect the market to continue its upbeat momentum. When they are not expecting huge ups and downs in the market in the short run, they can update their equity portfolio by including ATM put options in to it at an ideal size of 0.55 so that it is expected to provide an approximate hedge gain of $71.61 \%$. Even in the growth phase, unexpected down fall in the price level can be expected due to corrective nature of the financial markets, and for limiting the effects of such drop, the use of OTM put options at an ideal level of 0.51 fetches an average hedge gain of $63.29 \%$. Further, for the investors with extreme pessimistic outlook, the DOTM put options may provide $18.83 \%$ hedge effectiveness, if used with the equity assets at a ratio 0.14 . Investors who are ready for trading in equity options for assured profits can opt for ITM or DITM options, as per their willingness to pay for the hedge, to be included in the portfolio to be hedged at an optimal hedge size of 0.57 or 0.85 , respectively, expecting an approximate hedge gain of $56.88 \%$ and $78.33 \%$, respectively.

\section{Conclusion}

The prime focus of the current study is to compare the resistance level of the Indian equity options market to protect the current as well as the potential investments from detrimental consequences of undesirable changes in the underlying equity market, in respect of two diverse optimistic dimensions, the first one being a recovery trend and the other being a growth phase. Post confirming the ability of both the call and put options markets with different levels of exercisability by establishing the presence of integration of the market pairs and by estimating the time required by the market segments for regaining the integration from deviances due to asymmetric informational absorption, ideal hedge sizes and the resulting hedge gains are evaluated for both recovery and growth dimensions, following minimum variance framework.

The study figures out that the call options in the recovery phase prove to have relatively higher hedging gains while the risk reduction from ideal hedging using calls in the growth phase is lesser, denoting that when the market trend expresses to have endeavors to regain its earlier price level, the prospective investors can protect the effects from the price hikes by opting to long in the call options market. The ideal hedging using put options result in fairly higher gains both in the recovery period and the growth phase, signifying that the equity options are attractive for the existing investors in a bullish equity market as they provide an assured protection from the effects of unanticipated collapses in the price level. It is also noteworthy that the hedging gains are comparatively larger in the recovery phase than in the growth phase. As the recovery phase handles more risk than the growth phase, where the former attempts to regain a lost position whereas the latter tries to move further upward to reach new heights, the equity options market is supportive to the market participants by facilitating more efficient risk reduction from ideal hedging practices. In both the market sentimentalities under consideration, DOTM calls and puts provide only reduced hedge gains, indicating that the extremely un-exercisable options cannot provide greater hedging effectiveness, but it should also be noted that the optimal risk reductions from them are possible by using either calls or puts at a nominal hedge size.

Even though the futures segment in India reportedly offers higher hedge gains (Gupta \& Singh, 2009; Lagesh \& Padhi, 2009; Jose \& Lazar, 2015; Singh, 2017), the study proposes that the investors who are eager to mitigate their risk exposures to greater extents, without compromising the profits from fortunate market momentum, can choose blends of futures and options to result in a better hedge portfolio, as indicated in Ryu and Yang (2017) and Ahn, Bi, and Sohn (2018), but such probabilities remain open for further realistic investigations. Considering the fact that an upbeat market is always subject to corrective movements, the current study further leaves an avenue for future empirical analysis to reflect the market on such corrective trends. An inclusion of such varying trends during a day would also have been a greater assistance to the investors for assuring at most profitability from their enlightened decisions.

\section{References}

Abhyankar, A. H. (1995). Return and volatility dynamics in FT-SE 100 stock index and stock index futures markets. The Journal of Finance, 15(4), 457-488. https://doi.org/10.1002/fut.3990150405 
Aggarwal, N., \& Gupta, M. (2009). Empirical evidence on the efficiency of index options market in India. Asia-Pacific Business Review, 5(3), 106-116. https://doi.org/10.1177\%2F097324700900500311

Ahn, K., Bi, Y., \& Sohn, S. (2018). Price discovery among SSE 50 Index-based spot, futures and options markets. Journal of Futures Market, 39(2), 01-22. https://doi.org/10.1002/fut.21970

Alexander, C., \& Nogueira, L. M. (2007). Model Free Hedge Ratios and Scale Invariant Model. Journal of Banking and Finance, 31(6), 1839-1861. https://doi.org/10.1016/j.jbankfin.2006.11.011

An, Y., \& Suo, W. (2009). An empirical comparison of option pricing models in hedging exotic options. Financial Management, 38(4), 889-914. Retrieved from https://www.jstor.org/stable/40388698

Bagchi, D. (2012). Cross-sectional analysis of emerging market volatility index (India VIX) with portfolio returns. International Journal of Emerging Markets, 7(4), 383-396. https://doi.org/10.1108/17468801211264306

Bai, Y., Pan, Z., \& Liu, L. (2019). Improving futures hedging performance using option information: Evidence from the S\&P 500 index. Finance Research Letters, 28, 112-117. https://doi.org/10.1016/j.frl.2018.04.014

Bakshi, G., Cao, C., \& Chen, Z. (1997). Empirical performance of alternative option pricing models. The Journal of Finance, 52(5), 2003-2049. https://doi.org/10.2307/2329472

Bakshi, G., Cao, C., \& Chen, Z. (2000a). Pricing and hedging long-term options. Journal of Econometrics, 94(1-2), 277-318. https://doi.org/10.1016/S0304-4076(99)00023-8

Bakshi, G., Cao, C., \& Chen, Z. (2000b). Do call prices and underlying stock always move in the same direction?. The Review of Financial Studies, 13(3), 549-584. Retrieved from https://www.jstor.org/stable/2645996

Bhaduri, S. N., \& Durai, S. R. (2008). Optimal hedge ratio and hedging effectiveness of stock index futures; evidence from India. Macroeconomics and Finance in Emerging Market Economies, 1(1), 121-134. https://doi.org/10.1080/17520840701859856

Black, F., \& Scholes, M. (1973). The pricing of options and corporate liabilities. Journal of Political Economy, 81(3), 637-654. Retrieved from https://www.jstor.org/stable/1831029

Bond, G. E., \& Thompson, S. R. (1985). Risk aversion and the recommended hedging ratio. American Journal of Agricultural Economics, 67(4), 870-872. https://doi.org/10.2307/1241828

Brailsford, T., Corrigan, K., \& Heaney, R. (2001). A comparison of measures of hedging effectiveness: a case study using the Australian all ordinaries share price index futures contract. Journal of Multinational Financial Management, 11(4-5), 465-481. https://doi.org/10.1016/S1042-444X(01)00036-6

Butterworth, D., \& Holmes, P. (2001). The hedging effectiveness of stock index futures: evidence for the FTSE-100 and FTSE-mid250 indexes traded in the UK. Applied Financial Economics, 11(1), 27-68. https://doi.org/10.1080/09603100150210264

Cao, C., \& Huang, J.-Z. (2007). Determinants of S\&P 500 Index Options. Review of Derivatives Research, 10, 1-38. https://doi.org/10.1007/s11147-007-9015-5

Cecchetti, S. G., Cumby, R. E., \& Figlwiski, S. (1988). Estimation of optimal futures hedge. The Review of Economics and Statistics, 70(4), 623-630. https://doi.org/10.2307/1935825

Chakravarthy, S., Gulen, H., \& Mayhew, S. (2004). Informed trading in stock and option market. The Journal of Finance, 59(3), 1235-1257. Retrieved from https://www.jstor.org/stable/3694735

Chan, K., Chung, Y. P., \& Johnson, H. (1993). Why option prices lag stock prices: A trading based explanation. The Journal of Finance, 48(5), 1957-1967. https://doi.org/10.2307/2329075

Chen, S.-S., Lee, C.-f., \& Shrestha, K. (2003). Futures hedge ratios: a review. The Quarterly Review of Economics and Finance, 43(3), 433-465. https://doi.org/10.1016/S1062-9769(02)00191-6

Chen, S.-S., Lee, C.-f., \& Shrestha, K. (2008). Do the pure martingale and joint normality hypotheses hold for futures contracts? Implications for the optimal hedge ratios. The Quarterly Review of Economics and Finance, 48(1), 153-174. https://doi.org/10.1016/j.qref.2005.10.002

Choudhry, T. (2004). The hedging effectiveness of constant and time varying hedge ratios using three pacific basin stock futures. International Review of Economics and Finance, 13(4), 371-385. https://doi.org/10.1016/j.iref.2003.04.002 
Chuang, C.-C., Wang, Y.-H., Yeh, T.-J., \& Chuang, S.-L. (2015). Hedging effectiveness of the hedged portfolio: the expected utility maximization subject to the value-at-risk approach. Applied Economics, 47(20), 2040-2052. https://doi.org/10.1080/00036846.2014.1000528

Debasish, S. S. (2009). An econometric analysis of the lead-lag relationship between India's NSE Nifty and its derivative contracts. The Journal of Risk Finance, 10(4), 350-364. https://doi.org/10.1108/15265940910980650

DeMaskey, A. L. (1995). A comparison of the effectiveness of currency futures and currency options in the context of foreign exchange risk management. Managerial Finance, 21(4), 40-51. https://doi.org/10.1108/eb018511

Dixit, A., Yadav, S. S., \& Jain, P. (2010). Informational Efficiency of Implied Volatilities of S\&P CNX Nifty Index Options: A Study in Indian Securities market. Journal of Advances in Management Research, 7(1), 32-57. https://doi.org/10.1108/09727981011042847

Dumas, B., Fleming, J., \& Whaley, R. E. (1998). Implied volatility functions: empirical tests. The Journal of Finance, 53(6), 2059-2106. Retrieved from https://www.jstor.org/stable/117461

Easley, D., O'Hara, M., \& Sreenivas, P. (1998). Option volume and stock prices: evidence on where informed traders trade. The Journal of Finance, 53(2), 431-465. Retrieved from https://www.jstor.org/stable/117358

Ederington, L. H. (1979). The hedging performance of the new futures market. The Journal of Finance, 34(1), 157-170. https://doi.org/10.2307/2327150

Evnine, J., \& Rudd, A. (1984). Index options: the early evidence. The Journal of Finance, 40(3), 743-756. https://doi.org/10.2307/2327798

Fama, E. (1970). Efficient capital markets: a review of theory and empirical work. The Journal of Finance, 25(2), 383-417. https://doi.org/10.2307/2325486

Fleming, J., Ostdick, B., \& Whaley, R. E. (1996). Trading costs and the relative rates of price discovery in stock, futures and option markets. The Journal of Futures Market, 16(4), 353-387. https://doi.org/10.1002/(SICI)1096-9934(199606)16:4\%3C353::AID-FUT1\%3E3.0.CO;2-H

Floros, C., \& Vougas, D. V. (2006). Hedging effectiveness in greek stock index futures market. Applied Financial Economics, 14(15), 1125-1136. https://doi.org/10.1080/09603100412331297702

François, P., Gauthier, G., \& Godin, F. (2014). Optimal hedging when the underlying asset follows a regime-switching Markov process. European Journal of Operational Research, 237(1), 312-322. https://doi.org/10.1016/j.ejor.2014.01.034

Gupta, K., \& Singh, B. (2009). Estimating the optimal hedge ratio in the indian equity futures market. Journal of Financial Risk Management, 38-98.

Hentze, S., \& Seiler, M. J. (2000). An examination of the lead/lag relationship between the option market and the stock market: where do we stand?. Quarterly Journal of Business and Economics, 39(1), 35-48. Retrieved from https://www.jstor.org/stable/40473282

Holowczak, R., Simaan, Y. E., \& Wu, L. (2006). Price Discovery in the US stock and stock option markets: A portfolio approach. Review of Derivatives Research, 9, 37-65. https://doi.org/10.1007/s11147-006-9004-0

Hull, J., \& White, A. (2017). Optimal delta hedging for options. Journal of Banking and Finance, 82, 180-190. https://doi.org/10.1016/j.jbankfin.2017.05.006

Jiang, G. J., \& Tian, Y. S. (2011). A Random Walk Down the Options Market. The Journal of Futures Market, 32(6), 505-535. https://doi.org/10.1002/fut.20528

Jose, B., \& Lazar, D. (2015). Should investor invest in both future and spot market?: An analysis through optimal hedge ratio. Asian Business Review, 21-29.

Kamara, A., \& Miller, T. W. (1995). Daily and intradaily test of European put-call parity. The Journal of Financial and Quantitative Analysis, 30(4), 519-539. https://doi.org/10.2307/2331275

Kamara, A., \& Siegel, A. F. (1987). Optimal hedging in futures markets with multiple delivery specifications. The Journal of Finance, (42), 1007-1021. https://doi.org/10.2307/2328303

Kang, J., \& Park, H.-J. (2014). How informed investors take advantage of negative information in options and stock market. The Journal of Futures Market, 34(6), 516-547. https://doi.org/10.1002/fut.21651 
Kenourgios, D., Samitas, A., \& Drosos, P. (2008). Hedge ratio estimation and hedging effectiveness: the case of the S\&P 500 stock index futures contract. International Journal of Risk Assessment and Management, 153-174.

Kim, S., Kim, I. J., \& Nam, S. O. (2009). The lead lag relationship between stock index options and the stock index market; model, moneyness and news. International Journal of Managerial Finance, 5(3), 311-332. https://doi.org/10.1108/17439130910969738

Kumar, B., Singh, P., \& Pandey, A. (2008). Hedging effectiveness of constant and time varying hedge ratio in indian stock and commodity futures markets. SSRN Electronic Journal, 1-36. https://doi.org/10.2139/ssrn.1206555

Lagesh, M., \& Padhi, P. (2009). Evaluating the hedging performance of the constat and dynamic model in the Indian stock index futures market. Journal of Quantitative Economics, 78-92.

Lien, D. (2009). A note on the hedging effectiveness of Garch model. International Review of Economics and Finance, 110-112.

Lien, D., \& Tse, Y. K. (1999). Fractional cointegration and futures hedging. The Journal of Futures Markets, 19(4), 457-474. https://doi.org/10.1002/(SICI)1096-9934(199906)19:4\%3C457::AID-FUT4\%3E3.0.CO;2-U

Lien, D.-H. D. (1996). The effect of the cointegration relationship on futures hedging: A note. The Journal of

Markets,

16(7),

773-780. https://doi.org/10.1002/(SICI)1096-9934(199610)16:7<773::AID-FUT3>3.0.CO;2-L

Manaster, S., \& Rendleman, R. J. (1982). Option prices as predictors of equilibrium stock prices. Journal of Finance, 37(4), 1043-1057. https://doi.org/10.2307/2327766

Mazouz, K., Wu, Y., \& Yin, S. (2015). Trading Activity in Options and Stock around Price - Sensitive News Announcements. Journal of Futures Market, 35(12), 1173-1194. https://doi.org/10.1002/fut.21691

Mukharjee, K. N., \& Mishra, R. (2004). Impact of open interest and trading volume in option market on underlying cash market: empirical evidence from Indian equity options market. SSRN Electronic Journal, 1-22. https://doi.org/10.2139/ssrn.695745

Muravyev, D., Pearson, N. D., \& Broussard, J. P. (2013). Is there price discovery in equity options?. Journal of Financial Economics, 107(2), 259-283. https://doi.org/10.1016/j.jfineco.2012.09.003

Mutum, K., \& Das, A. K. (2019). Lower boundary conditions and pricing efficiency testing of indian index options market: empirical evidence from Nifty 50 Index. Indian Journal of Finance, 13(3), 26-38. https://doi.org/10.17010/ijf/2019/v13i3/142266

Park, T. H., \& Switzer, L. N. (1995a). Time varying distributions and the optimal hedge ratios for stock index futures. Applied Financial Economics, 5(3), 131-137. https://doi.org/10.1080/758523000a

Park, T. H., \& Switzer, L. N. (1995b). Bivariate GARCH estimation of the optimal hedge ratios for stock index futures: a note. The Journal of Futures Market, 15(1), 61-67. https://doi.org/10.1002/fut.3990150106

Rao, S. N., \& Thakur, S. K. (2008). Optimal hedge ratio and hedge efficiency: an empirical investigation of hedging in Indian derivatives market. Society of Actuaries, Monograph Publication, 1-27.

Ren, F., Ji, S.-D., Cai, M.-L., Li, S.-P., \& Jiang, X.-F. (2019). Dynamic lead-lag relationship between stock indices and their derivatives: A comparative study between Chinese mainland, Hong Kong and US stock markets. Physica A: Statistical Mechanics and Its Applications, 513, 709-723. https://doi.org/10.1016/j.physa.2018.08.117

Ross, S. A. (1976). Options and efficiency. The Quarterly Journal of Economics, 90(1), 75-89. https://doi.org/10.2307/1886087

Ryu, D. (2016). Considering all microstructure effects: the extension of a trade indicator model. Economics Letters, 146, 107-110. https://doi.org/10.1016/j.econlet.2016.07.025

Ryu, D., \& Yang, H. (2017). Price disagreements and adjustments in index derivatives markets. Economics Letters, 151, 104-106. https://doi.org/10.1016/j.econlet.2016.12.016

Shaikh, I., \& Padhi, P. (2013). On the Linkages among Ex-ante and Ex-post Volatility: Evidence from NSE Options Market (India). Global Business Review, 14(3), 487-505. https://doi.org/10.1177\%2F0972150913496866 
Shaikh, I., \& Padhi, P. (2015). On the Relationship of Ex-ante and Ex-post Volatility: A Sub-period Ananlysis of S\&P CNX Nifty Index Options. Journal of Emerging Market Finance, 14(2), 140-175. https://doi.org/10.1177\%2F0972652715584266

Singh, G. (2017). Estimating optimal hedge ratio and hedging effectiveness in the NSE index futures. Jindal Journal of Business Research, 6(2), 108-131. https://doi.org/10.1177\%2F2278682117715358

Srivastava, S. (2003). Informational content of trading volume on open interest: an empirical analysis of stock option market in India. SSRN Electronic Journal, 1-26. https://doi.org/10.2139/ssrn.606121

Vipul. (2008). Cross market efficiency in the Indian derivative market: A test of put-call parity. The Journal of Futures Markets, 28(9), 889-910. https://doi.org/10.1002/fut.20325

Yang, H., Lee, J., \& Ryu, D. (2017). Market depth, domestic investors and price monotonicity violations. Applied Economics Letters, 25(10), 688-692. https://doi.org/10.1080/13504851.2017.1355539

Zhang, H., \& Watada, J. (2019). An Analysis of the Arbitrage Efficiency of the Chinese SSE 50ETF Options Market. International Review of Economics and Finance, 59, 474-489. https://doi.org/10.1016/j.iref.2018.10.011

Zhipang, Y., \& Shenghong, L. (2017). Hedge ratio on markov regime switching diagonal Bekk GARCH model. Finance Research Letters, 24, 49-55. https://doi.org/10.1016/j.frl.2017.06.015

\section{Appendix A}

\section{Results of Preliminary Analysis and GARCH Estimation}

Table A1. Results of unit root tests for the data from the stock and options markets

\begin{tabular}{|c|c|c|c|c|c|c|c|c|}
\hline & \multicolumn{4}{|c|}{$\mathrm{ADF}$} & \multicolumn{4}{|c|}{$\mathrm{PP}$} \\
\hline & \multicolumn{2}{|c|}{ Level } & \multicolumn{2}{|c|}{ Diff. } & \multicolumn{2}{|c|}{ Level } & \multicolumn{2}{|c|}{ Diff. } \\
\hline & $\mathrm{t}$ & $\mathrm{p}$ & $\mathrm{t}$ & $\mathrm{p}$ & $\mathrm{t}$ & $\mathrm{p}$ & $\mathrm{t}$ & $\mathrm{p}$ \\
\hline \multicolumn{9}{|c|}{ Part 1 - The Recovery Phase } \\
\hline \multicolumn{9}{|c|}{ Panel A: Actual index } \\
\hline Spot & -2.24 & 0.46 & -34.26 & 0.00 & -2.22 & 0.48 & -34.25 & 0.00 \\
\hline \multicolumn{9}{|c|}{ Panel B: Implied index for Call options } \\
\hline ATM & -2.26 & 0.46 & -36.44 & 0.00 & -2.20 & 0.49 & -36.46 & 0.00 \\
\hline OTM & -2.24 & 0.47 & -36.86 & 0.00 & -2.19 & 0.49 & -36.86 & 0.00 \\
\hline ITM & -2.25 & 0.46 & -35.67 & 0.00 & -2.23 & 0.47 & -35.68 & 0.00 \\
\hline DOTM & -2.63 & 0.27 & -24.44 & 0.00 & -2.53 & 0.31 & -41.18 & 0.00 \\
\hline DITM & -2.25 & 0.46 & -34.71 & 0.00 & -2.23 & 0.47 & -34.71 & 0.00 \\
\hline \multicolumn{9}{|c|}{ Panel C: Implied index for Put options } \\
\hline ATM & -2.55 & 0.30 & -36.92 & 0.00 & -2.44 & 0.36 & -37.03 & 0.00 \\
\hline OTM & -2.55 & 0.30 & -36.64 & 0.00 & -2.45 & 0.35 & -36.75 & 0.00 \\
\hline ITM & -2.48 & 0.34 & -37.03 & 0.00 & -2.39 & 0.39 & -37.11 & 0.00 \\
\hline DOTM & -2.47 & 0.34 & -39.91 & 0.00 & -2.56 & 0.30 & -40.30 & 0.00 \\
\hline DITM & -2.35 & 0.41 & -36.93 & 0.00 & -2.27 & 0.45 & -36.96 & 0.00 \\
\hline \multicolumn{9}{|c|}{ Part 2 - The Growth Phase } \\
\hline \multicolumn{9}{|c|}{ Panel A: Actual index } \\
\hline Spot & -2.66 & 0.25 & -33.51 & 0.00 & -2.49 & 0.33 & -33.41 & 0.00 \\
\hline \multicolumn{9}{|c|}{ Panel B: Implied index for Call options } \\
\hline ATM & -3.13 & 0.10 & -42.24 & 0.00 & -2.93 & 0.15 & -46.15 & 0.00 \\
\hline OTM & -1.56 & 0.50 & -39.50 & 0.00 & -1.27 & 0.65 & -42.34 & 0.00 \\
\hline
\end{tabular}




\begin{tabular}{lcccccccc}
\hline ITM & -2.66 & 0.25 & -36.75 & 0.00 & -2.51 & 0.32 & -37.00 & 0.00 \\
\hline DOTM & -1.27 & 0.64 & -13.85 & 0.00 & -2.54 & 0.11 & -78.88 & 0.00 \\
\hline DITM & -2.59 & 0.28 & -36.74 & 0.00 & -2.58 & 0.29 & -36.74 & 0.00 \\
\hline Panel C: Implied index for Put options & & & & & & & \\
\hline ATM & -1.74 & 0.41 & -38.56 & 0.00 & -1.58 & 0.49 & -39.23 & 0.00 \\
\hline OTM & -1.78 & 0.39 & -27.77 & 0.00 & -1.66 & 0.45 & -37.20 & 0.00 \\
\hline ITM & -2.76 & 0.21 & -40.10 & 0.00 & -2.68 & 0.24 & -40.41 & 0.00 \\
\hline DOTM & -2.22 & 0.20 & -28.01 & 0.00 & -2.35 & 0.16 & -70.13 & 0.00 \\
\hline DITM & -2.61 & 0.27 & -36.65 & 0.00 & -2.56 & 0.30 & -36.70 & 0.00 \\
\hline
\end{tabular}

Source: Calculations of the researcher

Table A2. Results of ARCH LM tests for heteroskedasticity in the data from the stock and options markets

\begin{tabular}{|c|c|c|c|c|c|c|c|c|}
\hline & \multicolumn{4}{|c|}{ Recovery Phase } & \multicolumn{4}{|c|}{ Growth Phase } \\
\hline & F Stat. & Prob. & Obs.*R-squared & $\begin{array}{c}\text { Prob. } \\
\text { (Chi Sq.) }\end{array}$ & F Stat. & Prob. & Obs.*R-squared & $\begin{array}{c}\text { Prob. } \\
\text { (Chi Sq.) }\end{array}$ \\
\hline \multicolumn{9}{|c|}{ Panel A: Actual index } \\
\hline SPOT & 2.97 & 0.09 & 2.97 & 0.09 & 3.19 & 0.07 & 3.19 & 0.07 \\
\hline \multicolumn{9}{|c|}{ Panel B: Implied index for Call options } \\
\hline ATM & 6.40 & 0.01 & 6.38 & 0.01 & 1.58 & 0.06 & 26.61 & 0.06 \\
\hline OTM & 2.02 & 0.02 & 22.02 & 0.02 & 1.52 & 0.08 & 25.62 & 0.08 \\
\hline ITM & 3.10 & 0.05 & 6.18 & 0.05 & 0.58 & 0.45 & 0.58 & 0.44 \\
\hline DOTM & 3.00 & 0.05 & 5.98 & 0.05 & 4.01 & 0.02 & 7.99 & 0.02 \\
\hline DITM & 2.27 & 0.02 & 18.01 & 0.02 & 1.01 & 0.32 & 1.01 & 0.32 \\
\hline \multicolumn{9}{|c|}{ Panel C: Implied index for Put options } \\
\hline ATM & 8.49 & 0.00 & 8.45 & 0.00 & 3.13 & 0.00 & 18.61 & 0.00 \\
\hline OTM & 9.52 & 0.00 & 9.46 & 0.00 & 1.99 & 0.06 & 11.90 & 0.06 \\
\hline ITM & 7.25 & 0.01 & 7.22 & 0.01 & 2.19 & 0.04 & 13.06 & 0.04 \\
\hline DOTM & 98.58 & 0.00 & 91.53 & 0.00 & 269.69 & 0.00 & 224.19 & 0.00 \\
\hline DITM & 7.27 & 0.01 & 7.24 & 0.01 & 2.19 & 0.09 & 6.57 & 0.09 \\
\hline
\end{tabular}

Source: Calculations of the researcher

Table A3. Results of D-BEKK GARCH estimation

\begin{tabular}{|c|c|c|c|c|c|c|c|c|c|c|}
\hline & \multicolumn{2}{|c|}{ ATM } & \multicolumn{2}{|c|}{ OTM } & \multicolumn{2}{|c|}{ ITM } & \multicolumn{2}{|c|}{ DOTM } & \multicolumn{2}{|c|}{ DITM } \\
\hline & Coeff. & Prob. & Coeff. & Prob. & Coeff. & Prob. & Coeff. & Prob. & Coeff. & Prob. \\
\hline \multicolumn{11}{|c|}{ Part 1 - The Recovery Phase } \\
\hline \multicolumn{11}{|c|}{ Panel A: Call Options } \\
\hline $\mathrm{C} 1$ & 0.00 & 0.10 & 0.00 & 0.14 & 0.00 & 0.03 & 0.00 & 0.03 & 0.00 & 0.08 \\
\hline $\mathrm{C} 2$ & 0.00 & 0.28 & 0.00 & 0.25 & 0.00 & 0.02 & 0.00 & 0.90 & 0.00 & 0.01 \\
\hline $\mathrm{M}(1,1)$ & 0.00 & 0.00 & 0.00 & 0.00 & 0.00 & 0.00 & 0.00 & 0.00 & 0.00 & 0.00 \\
\hline $\mathrm{M}(1,2)$ & 0.00 & 0.00 & 0.00 & 0.00 & 0.00 & 0.00 & 0.00 & 0.00 & 0.00 & 0.00 \\
\hline $\mathrm{M}(2,2)$ & 0.00 & 0.00 & 0.00 & 0.00 & 0.00 & 0.00 & 0.00 & 0.00 & 0.00 & 0.00 \\
\hline $\mathrm{A} 1(1,1)$ & 0.19 & 0.00 & 0.18 & 0.00 & 0.26 & 0.00 & 0.23 & 0.00 & 0.31 & 0.00 \\
\hline
\end{tabular}




\begin{tabular}{|c|c|c|c|c|c|c|c|c|c|c|}
\hline $\mathrm{A} 1(2,2)$ & 0.16 & 0.00 & 0.09 & 0.00 & 0.21 & 0.00 & 0.15 & 0.00 & 0.22 & 0.00 \\
\hline $\mathrm{B} 1(1,1)$ & 0.98 & 0.00 & 0.98 & 0.00 & 0.96 & 0.00 & 0.97 & 0.00 & 0.94 & 0.00 \\
\hline $\mathrm{B} 1(2,2)$ & 0.98 & 0.00 & 0.99 & 0.00 & 0.97 & 0.00 & 0.98 & 0.00 & 0.95 & 0.00 \\
\hline \multicolumn{11}{|c|}{ Panel B: Put Options } \\
\hline $\mathrm{C} 1$ & 0.00 & 0.25 & 0.00 & 0.22 & 0.00 & 0.66 & 0.00 & 0.23 & 0.00 & 0.36 \\
\hline $\mathrm{C} 2$ & 0.00 & 0.21 & 0.00 & 0.16 & 0.00 & 0.38 & 0.00 & 0.07 & 0.00 & 0.23 \\
\hline $\mathrm{M}(1,1)$ & 0.00 & 0.00 & 0.00 & 0.00 & 0.00 & 0.00 & 0.00 & 0.00 & 0.00 & 0.00 \\
\hline $\mathrm{M}(1,2)$ & 0.00 & 0.00 & 0.00 & 0.00 & 0.00 & 0.00 & 0.00 & 0.00 & 0.00 & 0.00 \\
\hline $\mathrm{M}(2,2)$ & 0.00 & 0.00 & 0.00 & 0.00 & 0.00 & 0.00 & 0.00 & 0.00 & 0.00 & 0.00 \\
\hline $\mathrm{A} 1(1,1)$ & 0.20 & 0.00 & 0.21 & 0.00 & 0.17 & 0.00 & 0.24 & 0.00 & 0.23 & 0.00 \\
\hline $\mathrm{A} 1(2,2)$ & 0.18 & 0.00 & 0.19 & 0.00 & 0.12 & 0.00 & 0.20 & 0.00 & 0.15 & 0.00 \\
\hline $\mathrm{B} 1(1,1)$ & 0.97 & 0.00 & 0.97 & 0.00 & 0.98 & 0.00 & 0.97 & 0.00 & 0.96 & 0.00 \\
\hline $\mathrm{B} 1(2,2)$ & 0.98 & 0.00 & 0.97 & 0.00 & 0.99 & 0.00 & 0.97 & 0.00 & 0.98 & 0.00 \\
\hline \multicolumn{11}{|c|}{ Part 2 - The Growth Phase } \\
\hline \multicolumn{11}{|c|}{ Panel A: Call Options } \\
\hline $\mathrm{C} 1$ & 0.00 & 0.00 & 0.00 & 0.00 & 0.00 & 0.00 & 0.00 & 0.00 & 0.00 & 0.01 \\
\hline $\mathrm{C} 2$ & 0.00 & 0.09 & 0.00 & 0.12 & 0.00 & 0.00 & 0.00 & 0.93 & 0.00 & 0.07 \\
\hline $\mathrm{M}(1,1)$ & 0.00 & 0.00 & 0.00 & 0.00 & 0.00 & 0.00 & 0.00 & 0.00 & 0.00 & 0.01 \\
\hline $\mathrm{M}(1,2)$ & 0.00 & 0.00 & 0.00 & 0.00 & 0.00 & 0.00 & 0.00 & 0.00 & 0.00 & 0.00 \\
\hline $\mathrm{M}(2,2)$ & 0.00 & 0.00 & 0.00 & 0.00 & 0.00 & 0.00 & 0.00 & 0.00 & 0.00 & 0.00 \\
\hline $\mathrm{A} 1(1,1)$ & 0.21 & 0.00 & 0.22 & 0.00 & 0.26 & 0.00 & 0.22 & 0.00 & 0.19 & 0.00 \\
\hline $\mathrm{A} 1(2,2)$ & 0.10 & 0.00 & 0.08 & 0.00 & 0.17 & 0.00 & 0.41 & 0.00 & 0.07 & 0.00 \\
\hline $\mathrm{B} 1(1,1)$ & 0.96 & 0.00 & 0.96 & 0.00 & 0.94 & 0.00 & 0.96 & 0.00 & 0.97 & 0.00 \\
\hline $\mathrm{B} 1(2,2)$ & 0.99 & 0.00 & 0.98 & 0.00 & 0.96 & 0.00 & 0.62 & 0.00 & 0.98 & 0.00 \\
\hline \multicolumn{11}{|c|}{ Panel B: Put Options } \\
\hline $\mathrm{C} 1$ & 0.00 & 0.01 & 0.00 & 0.01 & 0.00 & 0.00 & 0.00 & 0.00 & 0.00 & 0.00 \\
\hline $\mathrm{C} 2$ & 0.00 & 0.04 & 0.00 & 0.04 & 0.00 & 0.01 & 0.00 & 0.60 & 0.00 & 0.01 \\
\hline $\mathrm{M}(1,1)$ & 0.00 & 0.00 & 0.00 & 0.00 & 0.00 & 0.00 & 0.00 & 0.00 & 0.00 & 0.00 \\
\hline $\mathrm{M}(1,2)$ & 0.00 & 0.00 & 0.00 & 0.00 & 0.00 & 0.00 & 0.00 & 0.00 & 0.00 & 0.00 \\
\hline $\mathrm{M}(2,2)$ & 0.00 & 0.00 & 0.00 & 0.00 & 0.00 & 0.00 & 0.00 & 0.00 & 0.00 & 0.00 \\
\hline $\mathrm{A} 1(1,1)$ & 0.14 & 0.00 & 0.15 & 0.00 & 0.21 & 0.00 & 0.25 & 0.00 & 0.54 & 0.00 \\
\hline $\mathrm{A} 1(2,2)$ & 0.10 & 0.00 & 0.11 & 0.00 & 0.18 & 0.00 & 0.35 & 0.00 & 0.47 & 0.00 \\
\hline $\mathrm{B} 1(1,1)$ & 0.97 & 0.00 & 0.97 & 0.00 & 0.95 & 0.00 & 0.95 & 0.00 & 0.70 & 0.00 \\
\hline $\mathrm{B} 1(2,2)$ & 0.98 & 0.00 & 0.98 & 0.00 & 0.96 & 0.00 & 0.64 & 0.00 & 0.73 & 0.00 \\
\hline
\end{tabular}

Source: Calculations of the researcher

\section{Copyrights}

Copyright for this article is retained by the author(s), with first publication rights granted to the journal.

This is an open-access article distributed under the terms and conditions of the Creative Commons Attribution license (http://creativecommons.org/licenses/by/4.0/). 